\title{
Fórum discute estratégias de combate à falsificação de medicamentos
}

\author{
Forum approaches strategies to tackle medicine adulteration
}

Agência Nacional de Vigilância Sanitária - Anvisa*

O consumo de medicamentos falsificados ou com desvios de qualidade por um paciente em tratamento pode agravar seu estado de saúde ou levá-lo à morte. Por serem formulados e fabricados clandestinamente, os produtos adulterados podem conter substâncias industriais tóxicas, o que também causaria sérios danos à saúde do usuário. Para que a fiscalização e a prevenção destas fraudes tenham maior resultado, detectou-se a necessidade de ações conjuntas, que reúnam todas as áreas envolvidas no processo, desde a produção até a comercialização de medicamentos. Pensando em fortalecer estas parcerias, a Anvisa promoveu nos dias 6 e 7 de julho, em Brasília, o Fórum Nacional de Prevenção e Combate à Falsificação e Fraude de Medicamentos, junto com a Organização Mundial de Saúde (OMS/OPAS).

Diversos representantes de instituições civis e entidades do governo ligados à área da Saúde compareceram para elaborar um plano de ação conjunta de prevenção a fraudes. Partindo do reconhecimento de que a luta contra a falsificação é uma responsabilidade que precisa ser compartilhada, os participantes discutiram estratégias que envolvem o fortalecimento da inspeção, o controle da cadeia de medicamentos, a criação de um sistema de informação e o aprimoramento da comunicação e divulgação de informações para o Sistema Nacional de Vigilância Sanitária (SNVS) entre outros aspectos para a articulação intersetorial.

Participaram da abertura do evento o Ministro da Saúde, Humberto Costa, e o Diretor- Presidente da Anvisa, Cláudio Maierovitch. Nos debates, o promotor público Humberto Medeiros defendeu uma campanha educativa para que usuários de medicamentos se tornem também agentes de controle, verificando o número dos lotes, prazos de validade, selos e outros dispositivos de segurança, podendo também acionar o Estado nos casos de denúncias. Já a representante da OMS Adriana Mitsue Ivama expôs um projeto nos quais setores interessados trabalham em modelo de rede, a exemplo das que já estão em funcionamento e são apoiadas pela OPAS/OMS. A proposta tem como objetivo a implantação do modelo para estabelecer e ampliar os laços de trabalho, facilitando a identificação de problemas.

Para o representante da Câmara Técnica de Vigilância Sanitária do Conselho Nacional de Secretários Estaduais de Saúde (Conass), atual Secretário Municipal de Saúde de São Paulo e ex Diretor-Presidente da Anvisa, Gonzalo Vecina Neto, "a fraude e o roubo de medicamentos no Brasil são, em muitos casos, conseqüências do fato desse produto não estar exatamente a serviço da saúde, e sim ser mais um instrumento para o lucro e, eventualmente, para a medicalização da sociedade". O secretário enfatizou ainda que a falsificação não é um problema policial, mas de assistência à saúde, com vários desdobramentos, sejam eles fiscais ou penais.

\section{HISTÓ RICO}

A falsificação e a fraude de medicamentos são problemas mundiais. No Brasil, entre 1997 e 1998, o Ministério da Saúde chegou a registrar 172 casos de falsificação, provocando questionamentos na sociedade sobre a qualidade e a segurança dos produtos comercializados nacionalmente. Várias medidas foram adotadas pelo governo a partir dessa crise, destacando a modificação da lei que tornou a falsificação um crime hediondo e a aprovação da Política Nacional de Medicamentos, que garante à população o acesso a medicamentos seguros e eficazes, ações reforçadas com a criação da Anvisa em 1999. Dentro da Agência, 
em 2001, foi criada a Gerência de Investigação, que tem entre suas atribuições a coordenação nacional do monitoramento da qualidade dos medicamentos. Após a criação da Anvisa, entre 1999 e 2003, apenas sete falsificações foram confirmadas.

\section{EXPERIÊNCIA DE SU CESSO}

Em novembro de 2002, por meio da $\operatorname{RDC~n}^{\circ} 320$, a Anvisa determinou a inclusão do número do lote de todos os produtos farmacêuticos comercializados pelas distribuidoras em suas notas fiscais. A medida auxiliou a monitoração do mercado, identificando vários lotes de medicamentos roubados no País desde a instituição da norma. Na época, em uma ação con- junta com a Vigilância Estadual de Minas Gerais, a Secretaria da Fazenda do Estado adotou a determinação como um instrumento de controle fiscal de medicamentos. Segundo o assessor do órgão, Marcos Vinícius Cunha, no início houve resistência, mas as ações judiciais foram vencidas pelo apelo sanitário da resolução. Ele afirma que várias foram as vantagens da ação, tanto para as entidades quanto para a população, como, por exemplo, em relação às penalidades. "Se a medida fosse adotada somente pela Secretaria da Fazenda poderíamos aplicar apenas a multa. Sendo uma ação conjunta com a Vigilância Sanitária, a fiscalização pode recolher o material caso o comerciante não comprove a procedência dos produtos" completa Marcos. 